\title{
Muscarinic Receptor Activity Induces an Afterdepolarization in a Subpopulation of Hippocampal CA1 Interneurons
}

\author{
A. Rory McQuiston and Daniel V. Madison \\ Department of Molecular and Cellular Physiology, Stanford University School of Medicine, Stanford, California 94305
}

\begin{abstract}
Cholinergic input to the hippocampus may be involved in important behavioral functions and the pathophysiology of neurodegenerative diseases. Muscarinic receptor activity in interneurons of the hippocampus may play a role in these actions. In this study, we investigated the effects of muscarinic receptor activity on the excitability of different subtypes of interneurons in rat hippocampal CA1. Most interneurons displayed an afterhyperpolarizing potential (AHP) after depolarization by injected current or synaptic stimulation. In the presence of a muscarinic agonist, the AHP of a subset of these interneurons was replaced by an afterdepolarization (ADP), often of sufficient magnitude to evoke action potentials in the absence of further stimulation. The ADP was insensitive to cadmium and low
\end{abstract}

extracellular calcium. It was blocked by low extracellular sodium but not by tetrodotoxin or low concentrations of amiloride. Muscarinic ADPs were sometimes observed in isolation but were often accompanied by depolarizing, hyperpolarizing, or biphasic changes in the membrane potential. Interneurons with muscarinic ADPs were found in all strata of CA1 and did not fall into a single morphological classification. The potential functions of the prolonged action potential output of interneurons produced by the ADP could include changes in hippocampal circuit properties and facilitation of the release of peptide cotransmitters in these interneurons.

Key words: muscarinic receptor; acetylcholine; hippocampus; CA1; interneuron; afterdepolarization
Acetylcholine (ACh) has an important role in normal hippocampal function and has been shown to have a variety of actions on both principal pyramidal neurons as well as interneurons. However, compared with its actions on principal cells, relatively little is known about the detailed effects of muscarinic receptor activity on interneurons. In hippocampal pyramidal cells, muscarinic receptor activity consistently produces a depolarization of the membrane potential and a blockade of a calcium-activated potassium conductance with a concomitant decrease in spike frequency accommodation (Benardo and Prince, 1982; Cole and Nicoll, 1983). It also generates afterdepolarizations or plateau potentials (Benardo and Prince, 1982; Frazer and MacVicar, 1996). Although some of the complex effects of muscarinic activity on interneuronal membrane potential are beginning to be understood (Benardo and Prince, 1982; Reece and Schwartzkroin, 1991; McQuiston and Madison, 1996; Parra et al., 1998), little is known about the effect of muscarinic receptor activity on the firing properties of interneurons in the hippocampus.

Hippocampal interneurons show a high degree of diversity in dendritic arborization, axonal termination regions, and probable function (for review, see Freund and Buzsaki, 1996). Evidence is beginning to accumulate that there is also a diversity of responsiveness to afferent neurotransmitters across hippocampal interneuronal populations (cf. Parra et al., 1998) that, at least in some cases, correlates with interneuronal morphology [accompanying

Received Nov. 30, 1998; revised April 9, 1999; accepted April 19, 1999.

This work was supported by National Institutes of Health Grants MH48874 and MH56454 to D.V.M. We thank Brie Linkenhoker for her helpful comments on this manuscript, Eric Schaible and Paul Pavlidis for writing the acquisition and analysis software, and David Prince and John Huguenard for allowing us use of the Neurolucida for neuronal reconstructions.

Correspondence should be addressed to Daniel V. Madison, Department of Molecular and Cellular Physiology, Beckman Center, Room 111b, Stanford University School of Medicine, Stanford, CA 94305-5345.

Copyright (C) 1999 Society for Neuroscience $0270-6474 / 99 / 195703-08 \$ 05.00 / 0$ article (McQuiston and Madison, 1999)]. Here, we investigate the effects of muscarinic receptor activity on the excitability of interneurons in all layers of rat hippocampal CA1. Effects of muscarinic agonists were tested across many different types of interneurons and assessed for correlation with their anatomical structures. We show that a subset of interneurons generate an afterdepolarizing potential (ADP) when stimulated in the presence of a muscarinic agonist and that this effect is distributed across a wide range of interneuronal morphologies.

\section{MATERIALS AND METHODS}

Young male rats (16- to 54-d-old) were anesthetized with halothane and killed by decapitation. Brains were rapidly removed and placed in cold $\left(4^{\circ} \mathrm{C}\right)$ oxygenated saline [(in mM): $\mathrm{NaCl} 119, \mathrm{KCl} 2.5, \mathrm{CaCl}_{2} 1.0, \mathrm{MgCl}_{2}$ $3, \mathrm{NaHPO}_{4} 1, \mathrm{NaHCO}_{3}$ 26.2, glucose 11, and kynurenic acid 1, pH 7.4]. Brains were hemisected; coronal slices (300- to $400-\mu$ m-thick) were cut on a Vibratome (Ted Pella Inc., St. Louis, MO) and submerged in an incubation chamber $\left(30^{\circ} \mathrm{C}, 30 \mathrm{~min}\right)$. Slices were then cooled to room temperature $\left(\sim 23^{\circ} \mathrm{C}\right)$ and recorded from over the next $2-4 \mathrm{hr}$.

Whole-cell patch-clamp recordings were made from visualized interneurons in all layers of area CA1 (MacVicar, 1984; Dodt and Zieglgansberger, 1990). Slices, on cover glass, were placed in a recording chamber mounted on the stage of a modified Nikon Optiphot 2 microscope (Technical Instruments, San Francisco, CA) and superfused with oxygenated saline [(in mM): $\mathrm{NaCl} 119, \mathrm{KCl} 2.5, \mathrm{CaCl}_{2} 2.5, \mathrm{MgSO}_{4}$ 1.3, $\mathrm{NaHPO}_{4} 1, \mathrm{NaHCO}_{3} 26.2$, and glucose $\left.11, \mathrm{pH} 7.4 ; 22-24^{\circ} \mathrm{C}\right]$. Neurons were visualized using near-infrared light $(40 \times$ magnification). Images were collected by a Hamamatsu C2400 intensified CCD camera (Hamamatsu Corporation, Bridgewater, $\mathrm{NJ}$ ) with contrast enhancement. The images were displayed on a video monitor, and glass patch pipettes were visually advanced through the slice to the surface of the cell from which to be recorded.

Patch pipettes were fabricated from borosilicate glass (KG33; $1.5 \mathrm{~mm}$ outer diameter, $1.0 \mathrm{~mm}$ inner diamter; Garner Glass Co., Claremont, CA) and filled with a HEPES-gluconate or methylsulfate buffer [(in $\mathrm{mm}$ ): $\mathrm{K}$ gluconate or $\mathrm{K}$ methlysulfate 130, $\mathrm{NaCl} \mathrm{8,} \mathrm{HEPES} \mathrm{10,} \mathrm{MgATP}$ 2, $\mathrm{Na}_{3}$ GTP 0.3 , and BAPTAK ${ }_{4} 0.1, \mathrm{pH}$ 7.25]. When neurobiotin $(0.5 \%)$ was included in the internal solution to label cells, $\mathrm{K}$ gluconate-methylsulfate was reduced to $120 \mathrm{~mm}$ to maintain osmolarity. Methylsulfate was 
preferred because, anecdotically, we felt that there was less rundown of ADPs when methylsulfate was used instead of gluconate. This is consistent with previous findings that methylsulfate better preserves the firing patterns of an individual neuron during whole-cell recording (Velumian et al., 1997).

Membrane potentials were monitored with an Axoclamp 2A amplifier (Axon Instruments, Foster City, CA), acquired through an MIO-16-E2 analog-to-digital interface (National Instruments, Austin, TX) onto a Pentium personal computer using software written in Labview (National Instruments) by members of our laboratory (Stanford, CA) (Eric Schaible and Paul Pavlidis). Data were analyzed using programs written in Labview and Axum (Mathsoft Inc., Cambridge, MA). ADPs were quantified by calculating the area under the ADP. Area was calculated by summing the amplitudes of all individual data samples over time, relative to the baseline of prestimulus membrane potential. Samples were summed from the end of the evoking depolarizing pulse to the point at which the membrane potential returned to the prestimulus level (indicated by a dashed line in the figures). Thus, an ADP had a positive value for area, whereas an afterhyperpolarizing potential (AHP) had a negative value. Statistical significance was determined by two-tailed unpaired Student's $t$ test for data of unequal variance. Values are reported as mean \pm SEM. Because muscarinic receptor activity often caused a change in the resting membrane potential, cells were always returned to the control resting potential by current injected through the recording electrode. This ensured that ADPs were always evoked from a consistent membrane potential within each cell, thus ensuring that any effect, drug, or treatment on an ADP was not secondary to a change in membrane potential.

All drugs were applied by bath superfusion. Muscarinic responses were produced by bath application of muscarine, carbachol, or ACh. Carbachol and acetylcholine were used in combination with the nicotinic antagonists $\alpha$-bungarotoxin $(\alpha$-BgTx) $(100 \mathrm{nM})$ and mecamylamine (MEC) $(10 \mu \mathrm{M})$ to prevent the activation of nicotinic receptors. Antagonists were applied to the tissue and equilibrated before the agonist was applied.

Neuronal morphology was visualized using neurobiotin or biocytin (Bolam, 1992). For histology, slices were fixed overnight in buffered $4 \%$ paraformaldehyde (containing $0.05 \%$ glutaraldehyde and $0.2 \%$ picric acid), embedded in gelatin, and sectioned $(100 \mu \mathrm{m})$. Sections were permeabilized ( $0.5 \%$ Triton X-100), treated with $0.3 \%$ hydrogen peroxide to reduce background peroxidase activity, and incubated overnight in avidin-biotin-peroxidase complex (Elite Vectastain ABC kit; Vector Laboratories, Burlingame, CA). Sections were stained with diaminobenzidine, intensified with nickel, mounted on slides, cleared, and coverslipped.

All chemicals were purchased from Fluka (Milwaukee, WI) except for the following: ( \pm )-muscarine, acetylcholine, $\alpha$-bungarotoxin, mecamylamine, and methyllycaconitine (Research Biochemicals, Natick, MA); tetrodotoxin (TTX) (Calbiochem, La Jolla, CA); and paraformaldehyde (Electron Microscopy Sciences, Fort Washington, PA).

\section{RESULTS}

We investigated the effect of muscarinic receptor activity on the firing properties of hippocampal CA1 interneurons using wholecell patch clamping. We applied $600 \mathrm{msec}$ depolarizing current injections to evoke a train of action potentials (typically $120 \mathrm{pA}$ ).

\section{Muscarinic receptor activity produces an afterdepolarizing potential in some CA1 interneurons}

A subset of interneurons in all layers of CA1 exhibited increased excitability when treated with muscarinic agonists. Trains of action potentials induced by injecting depolarizing current through the recording electrode were generally followed by small AHPs (Fig. $1 A, B$, left $)$. In some $(\sim 15 \%)$ interneurons, muscarine (10 $\mu \mathrm{M})$ caused the replacement of the AHP with a large and longlasting ADP. This ADP was usually sufficiently large to itself elicit a prolonged burst of action potentials from an interneuron (Fig. $1 A, B$, middle). These ADPs varied considerably in duration from several hundred milliseconds (Fig. $1 A$ ) to several seconds (Fig. $1 B)$. The effects of muscarinic agonist in producing an ADP were reversible (Fig. 1A,B, right). ADPs were seen in a total of 97 (of $\sim 650$ ) interneurons located in all layers of CA1 (Table 1).

The mean values for the area of the afterpotentials are plotted in Figure $1 C$. In 85 interneurons, muscarinic receptor activity
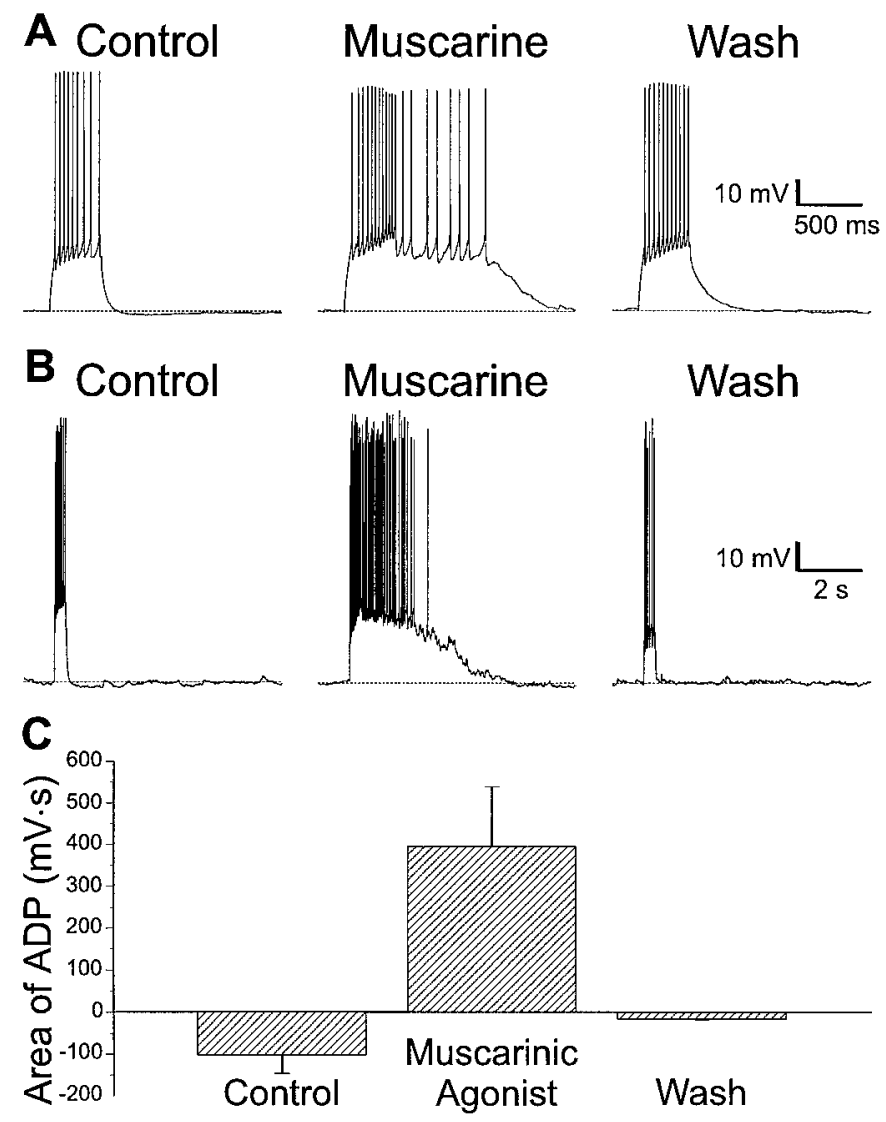

Figure 1. An ADP is produced in some interneurons during muscarinic receptor activity in CA1 interneurons. $A$, Injection of depolarizing current $(600 \mathrm{msec}, 120 \mathrm{pA})$ into an interneuron in SR evoked an accommodating train of action potentials followed by a small AHP (left). Application of muscarine $(10 \mu \mathrm{M})$ resulted in an ADP after current injection of several hundred milliseconds duration that supported a burst of action potentials (middle). The effect of muscarine was reversible after removal of the agonist (right). B, In an SLM interneuron, depolarizing current $(600 \mathrm{msec}, 120 \mathrm{pA})$ resulted in a train of action potentials followed by a small AHP (left). Addition of muscarine $(10 \mu \mathrm{M})$ resulted in an ADP lasting several seconds (middle). These effects of muscarine were reversible (right). $C$, Summary plot of ADPs in response to muscarine from 85 interneurons in CA1. Plotted are the means of the area under the afterpotentials relative to the resting membrane potential before, during, and after muscarine application. Positive values indicate an ADP; negative values indicate an AHP.

changed the AHP (area $-102 \pm 45 \mathrm{mV} \cdot \mathrm{sec})$ to ADP (area $395 \pm$ $144 \mathrm{mV} \cdot \sec ; p<0.005)$; when the drug was removed, the sign of the afterpotential area recovered (area $-16 \pm 4 \mathrm{mV} \cdot \mathrm{sec} ; p<$ 0.001).

Production of an ADP by application of muscarine was prevented by previous treatment with atropine. In the example shown in Figure $2 A$, application of muscarine $(10 \mu \mathrm{M})$ transformed an AHP (Fig. $2 A$, left) into an ADP (Fig. $2 A$, middle). Atropine $(1 \mu \mathrm{M})$ prevented this transformation (Fig. $2 A$, right). The results of these experiments are summarized in the plot of afterpotential areas shown in Figure $2 B$. Significant changes in afterpotential area were induced by muscarine (control area $-47 \pm 32 \mathrm{mV} \cdot \sec$ vs muscarine $118 \pm 44 \mathrm{mV} \cdot \sec ; p<0.05)$ Previous application of atropine $(1 \mu \mathrm{M})$ prevented any significant changes in area (atropine $-57 \pm 12 \mathrm{mV} \cdot \mathrm{sec}$ vs atropine plus muscarinic agonist $-67 \pm 16 \mathrm{mV} \cdot \mathrm{sec} ; p>0.63 ; n=3)$.

We observed that consecutive applications of muscarinic agonists did not produce ADPs of consistent magnitude. With re- 


\begin{tabular}{lccccc}
\hline \multicolumn{7}{l}{ Table 1. Distribution of interneurons displaying an ADP } & & & \\
& SO & SP & SR & SR/SLM & Total \\
\hline No Effect & 3 & 2 & 9 & 11 & $25(26 \%)$ \\
Depolarization & 5 & 3 & 17 & 8 & $33(34 \%)$ \\
Hyperpolarization & 0 & 0 & 19 & 6 & $25(26 \%)$ \\
Biphasic & 2 & 1 & 9 & 2 & $14(14 \%)$ \\
Total & $10(10 \%)$ & $6(6 \%)$ & $54(56 \%)$ & $27(28 \%)$ & $97(100 \%)$
\end{tabular}

Distribution of interneurons displaying ADPs in response to muscarine. The interneurons are categorized by anatomical location of their cell bodies and associated membrane voltage responses to muscarinic agonist.

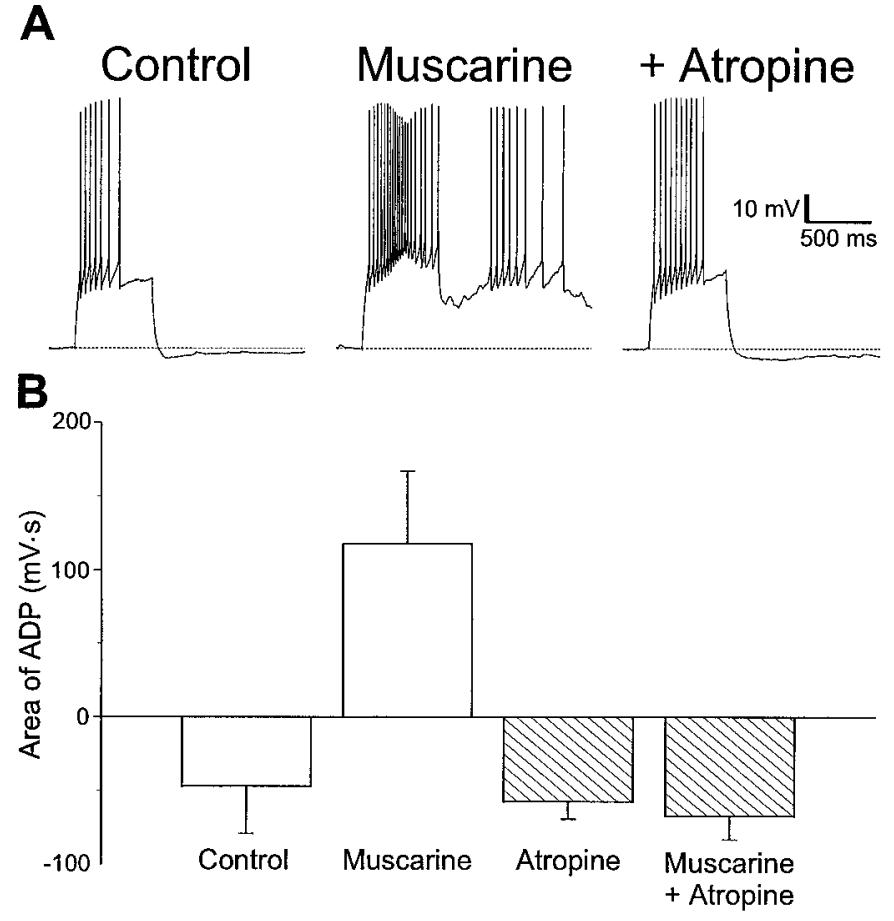

Figure 2. Inhibition of ADP production by atropine. $A$, Injection of depolarizing current into an interneuron in SR resulted in an accommodating train of action potentials followed by an AHP (left). In the presence of muscarine $(10 \mu \mathrm{M})$, action potential accommodation was reduced and the AHP was replaced by an ADP (middle). When atropine was also present $(1 \mu \mathrm{M})$, muscarine $(10 \mu \mathrm{M})$ did not produce an ADP (right). B, Summary plot of the area of the afterpotential in interneurons before and during the application of muscarinic agonist, in the absence (left $)$ and presence (right) of atropine (1-5 $\mu \mathrm{M})$. ADPs were not observed in atropine $(n=3)$.

peated application of muscarinic agonists, the area of the ADP progressively decreased. An example is shown in Figure 3. The first application of muscarine $(10 \mu \mathrm{M})$ produced an ADP (Fig. $3 A$, middle) in an interneuron that had previously responded to a depolarizing pulse with an AHP (Fig. $3 A$, left). After recovery from the first application of muscarine (Fig. 3, A, right, B, left), a second application of muscarine produced an ADP of smaller amplitude (Fig. 3B, middle). This reduction in amplitude was a consistent finding (Fig. 3C). The area of the ADPs from initial muscarinic applications $(161 \pm 39 \mathrm{mV} \cdot \sec ; n=15)$ were significantly greater than the ADPs measured after subsequent muscarinic applications $(47 \pm 9 \mathrm{mV} \cdot \sec ; n=15 ; p<0.02)$. We did not investigate the reason for the instability of the ADPs any further. The rundown of ADPs from one application of muscarine to the next made experiments investigating the ionic mechanism of the ADP difficult, because muscarine needed to be
A

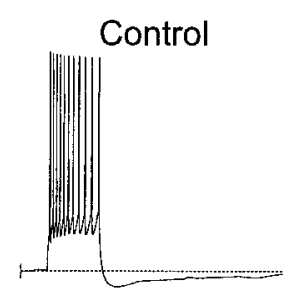

B
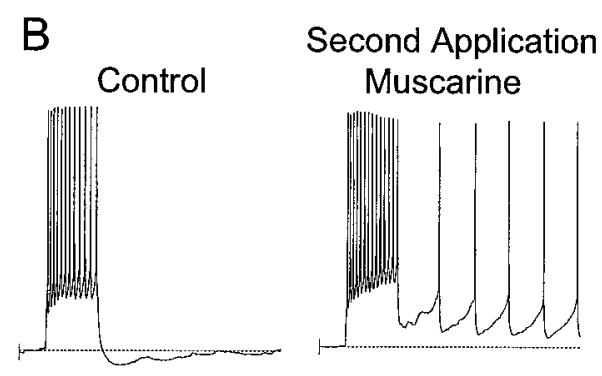
Muscarine
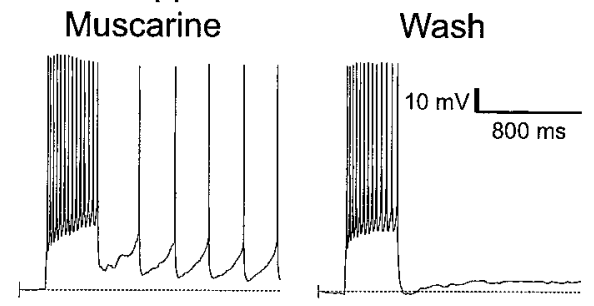

C

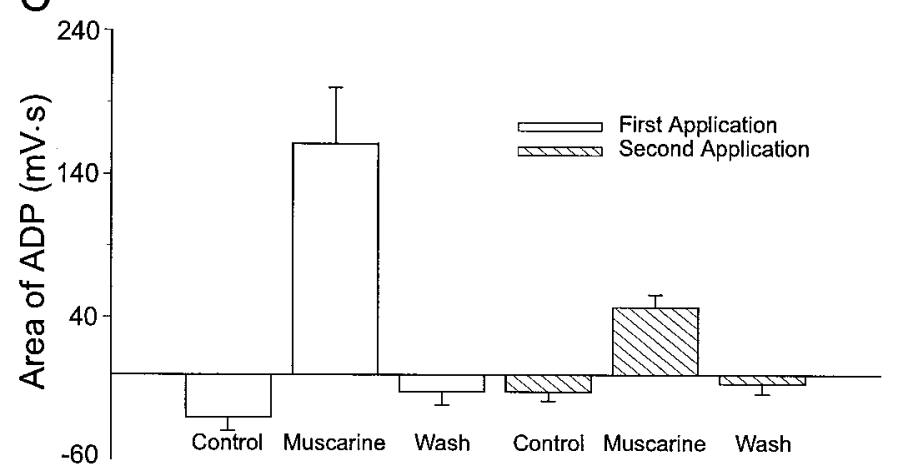

Figure 3. Effect of repeated applications of muscarine on the size of the ADPs. $A$, Initial application of muscarine $(10 \mu \mathrm{M})$ resulted in an ADP in response to an injection of depolarizing current $(600 \mathrm{msec}, 120 \mathrm{pA})$ (mid$d l e$ ), whereas an AHP was observed in response to the same current injection in the absence of muscarine (Control, Wash). B, A second application of muscarine $(10 \mu \mathrm{M})$ produced a smaller ADP (compare with $A$ ) in response to the same current injection (middle). $C$, Summary of the effects of consecutive applications of muscarinic agonists on the ADP. During a second application of muscarine, the area of the ADP is reduced $(n=15)$.

applied two or more times in different ionic conditions. To avoid this potential problem, we only analyzed those experiments in which there was clear recovery of the ADP after an inhibitory manipulation.

\section{Calcium influx is not required for stimulating a muscarinic ADP}

Previous studies on CA1 pyramidal cells (Fraser and MacVicar, 1996) and neocortical pyramidal cells (Schwindt et al., 1988; 

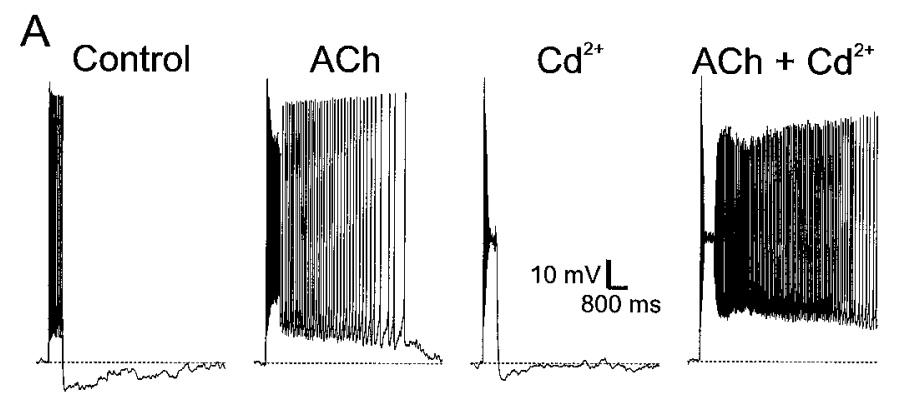

B
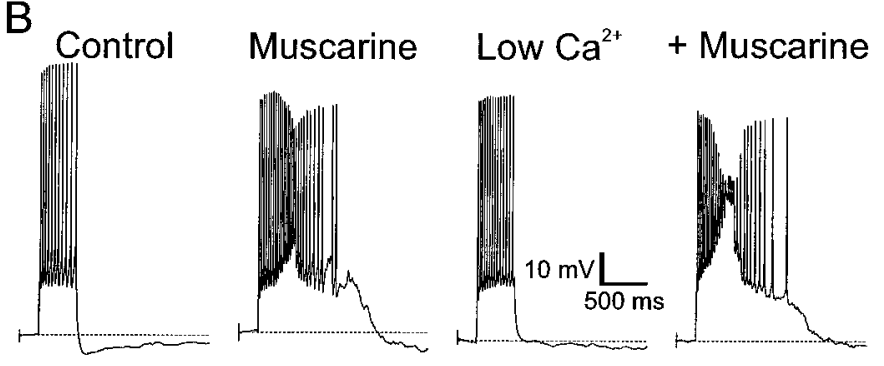

c

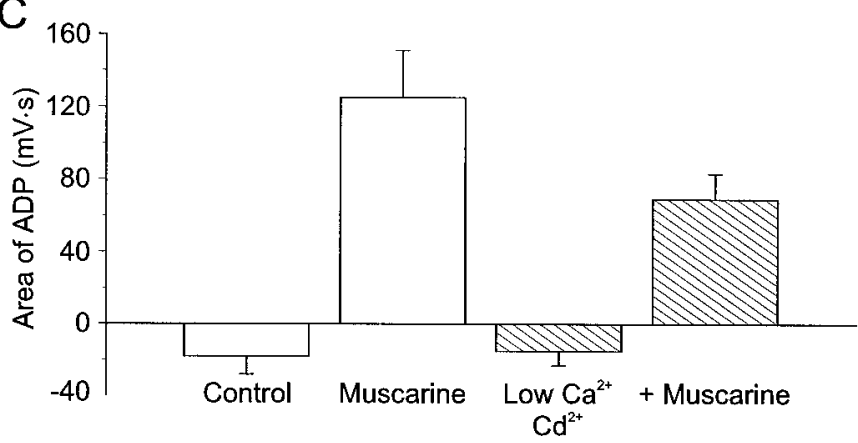

Figure 4. Calcium influx is not required for an ADP to occur. A, Left to right, injection of a depolarizing current injection $(600 \mathrm{msec}, 100 \mathrm{pA})$ into an interneuron in SR resulted in a train of accommodating action potentials followed by an AHP. ACh $(300 \mu \mathrm{M})$, in the presence of nicotinic receptor antagonists $(\alpha$-BgTx $100 \mathrm{nM}$; MEC $10 \mathrm{~mm})$ resulted in an ADP after the depolarizing current injection. Blockade of voltage-dependent calcium channels by $\mathrm{Cd}^{2+}(200 \mu \mathrm{M})$ produced a train of accommodating action potentials in response to an injection of depolarizing current. ACh (300 $\mu \mathrm{M})$, in the presence of $\mathrm{Cd}^{2+}(200 \mu \mathrm{M})$, still promoted an ADP after the current injection. B, Left to right, Injection of depolarizing current $(600$ msec, $120 \mathrm{pA}$ ) into an interneuron in SR resulted in a train of accommodating action potentials followed by an AHP. Bath application of muscarine $(10 \mu \mathrm{M})$ resulted in an ADP after the current injection. Low extracellular $\mathrm{Ca}^{2+}\left(0.1 \mathrm{mM} \mathrm{Ca}^{2+}-4 \mathrm{mM} \mathrm{Mg}^{2+}\right)$ reduced action potential accommodation and the AHP but did not prevent the muscarinic ADP. $C$, Summary of the effects of low $\mathrm{Ca}^{2+}$ and $\mathrm{Cd}^{2+}$ on the area of the ADPs. Muscarine did not block the activation of ADPs in the presence of $\mathrm{Cd}^{2+}$ or low extracellular $\mathrm{Ca}^{2+}$ in interneurons in all layers of CA1 $(n=11)$.

Andrade, 1991) showed that the muscarinic ADP in these cells resulted from activation of a calcium-activated nonselective cation current secondary to the influx of calcium through voltagedependent calcium channels (VDCCs) (Fraser and MacVicar, 1996). We tested whether the muscarinic ADP we observed in CA1 interneurons was caused by the activation of a similar current. Interneurons displaying muscarinic ADPs were treated with cadmium $(200 \mu \mathrm{M})$ to inhibit calcium influx through VDCCs. In control conditions, an interneuron that normally produced an AHP after a depolarizing pulse (Fig. 4A, Control) produced a large ADP after activation of muscarinic receptors [Fig. $4 A, A C h$ $(300 \mu \mathrm{M})$. After removal of ACh, application of cadmium produced a small plateau during the depolarization pulse; this was followed by a small AHP (Fig. $4 A, C d^{2+}$ ). However, an ADP was still produced when $\mathrm{ACh}$ was applied subsequently in the continued presence of cadmium (Fig. $4 A, A C h+C d^{2+}$ ).

Similar results were seen with low extracellular calcium. The interneuron in Figure $4 B$ produced an AHP after a depolarizing pulse (Control); addition of muscarine $(10 \mu \mathrm{M})$ resulted in an ADP (Fig. 4B, Muscarine). The neuron responded to low extracellular calcium $\left(0.1 \mathrm{mM} \mathrm{Ca}^{2+}-4 \mathrm{mM} \mathrm{Mg}^{2+}\right)$ with an increased firing rate and decreased amplitude of the AHP (Fig. 4B, Low $\mathrm{Ca}^{2+}$ ), but addition of muscarine still resulted in an ADP after a depolarizing pulse (Fig. 4B, +Muscarine). The survival of the muscarinic ADP in both cadmium and low calcium indicates that calcium influx is not required to activate the ADP.

The results of the experiments with cadmium and low calcium are summarized in Figure $4 C$. In the absence of calcium influx, muscarinic receptor activity significantly changed the area of the afterpotential (before muscarine, $-15 \pm 8 \mathrm{mV} \cdot \mathrm{sec}$; after muscarine, $69 \pm 14 \mathrm{mV} \cdot \sec ; p<0.0001 ; n=11)$. Although the muscarinic ADP produced in low $\mathrm{Ca}^{2+}$ or cadmium was somewhat smaller relative to the first application of muscarine $(125 \pm$ $26 \mathrm{mV} \cdot \mathrm{sec}$ vs low $\mathrm{Ca}^{2+}$-cadmium $\left.69 \pm 14 \mathrm{mV} \cdot \mathrm{sec} ; n=11\right)$, this reduction was not significant $(p>0.08)$. This decrease in the area of the ADP is likely caused by the rundown of the ADP.

\section{Sodium influx is required for ADP production}

Calcium-activated currents are only one of several mechanisms that have been identified as underlying ADPs. Short duration ADPs in CA1 pyramidal cells have been reported to be inhibited by TTX and are thought to arise from the activation of a persistent voltage-dependent sodium channel (VDSC) (Azouz et al., 1996). There is also evidence that the sodium-calcium exchanger in neocortical pyramidal cells may be responsible for plateau potentials observed in neocortical neurons when potassium channels are inhibited (Friedman et al., 1992). Therefore, we investigated the possibility that the ADP in interneurons was the result of opening of sodium channels or of sodium transport.

We first examined the possibility that muscarine was promoting the appearance of ADPs by potentiating a persistent TTXsensitive VDSC in CA1 interneurons (Crill, 1996). TTX (5 $\mu \mathrm{M})$ was applied to interneurons having muscarinic ADPs to block persistent VDSCs (Fig. $5 A$ ). This was done in the presence of cadmium $(500 \mu \mathrm{M})$ to block any calcium activated currents as well. Because TTX inhibited action potential generation (Fig. 5A, $T T X / C d^{2+}$ ), we increased the current amplitude to depolarize the membrane potential to the same voltage as the peak of the action potential. Under these conditions, application of muscarine continued to produce an ADP after the depolarizing pulse. Similar observations were seen in seven other cells exposed to TTX $(\mathrm{TTX}-4 \pm 3 \mathrm{mV} \cdot \mathrm{sec}$ vs muscarine plus TTX $69 \pm 16 \mathrm{mV} \cdot \mathrm{sec}$; $p<0.003 ; n=8$ ) (Fig. $5 B$ ). In this set of experiments, the area of the ADP in the presence of TTX was somewhat smaller than in the presence of muscarine alone but not significantly (muscarine $146 \pm 33 \mathrm{mV} \cdot \mathrm{sec}$ vs muscarine plus TTX $69 \pm 16 \mathrm{mV} \cdot \mathrm{sec} ; n=$ $8 ; p>0.06)$. This decrease could be caused by depolarization in the absence of action potentials being less effective in evoking an ADP or to the rundown of the ADP with repeated application of muscarine (Fig. 3). Rundown did still occur in the presence of TTX.

We next examined the possibility that the muscarinic ADP was the result of the activation of a TTX-insensitive sodium channel or the sodium-calcium exchanger. In these studies, extracellular $\mathrm{NaCl}$ was replaced with choline chloride. In normal saline, muscarine $(10 \mu \mathrm{M})$ induced an ADP after injection of a depolarizing 
A

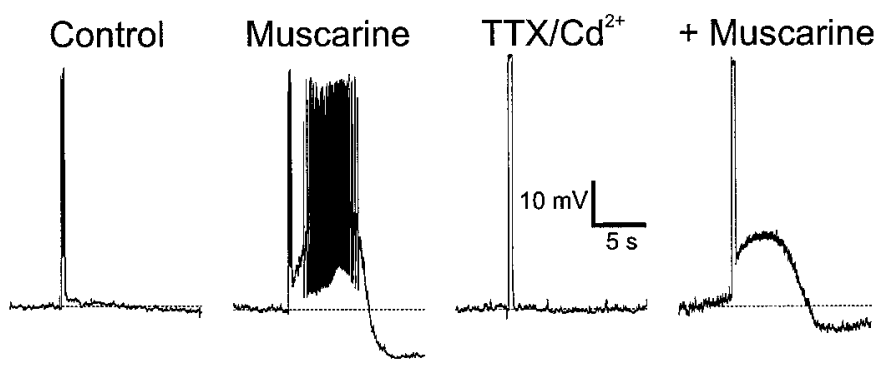

B

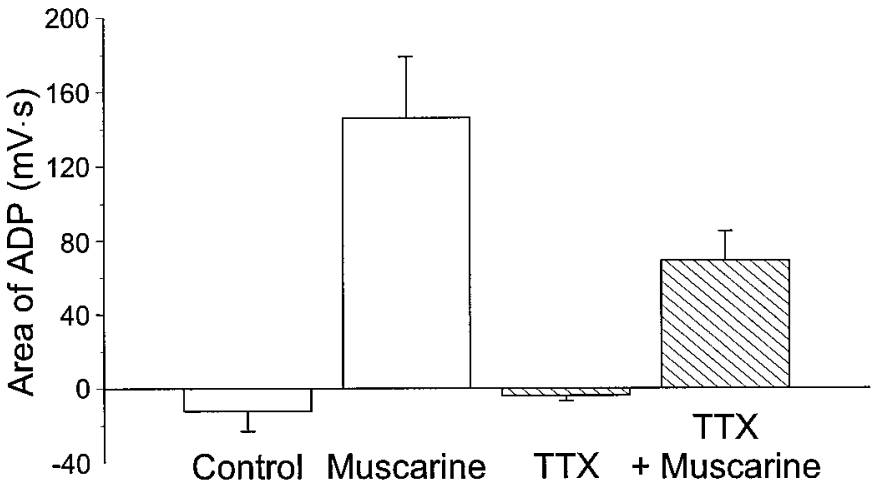

Figure 5. Activation of TTX-sensitive sodium channels is not required for ADPs. A, Left to right, Injection of depolarizing current (600 msec, 120 pA) into an interneuron in SR produced a train of action potentials. Muscarine $(10 \mu \mathrm{M})$ resulted in a large ADP that lasted for several seconds. Bath application of TTX $(5 \mu \mathrm{M})$ and $\mathrm{Cd}^{2+}(200 \mu \mathrm{M})$ blocked action potentials but not the muscarine-induced ADP after depolarizing current injection, to give a depolarization equal to the action potential peak (600 msec, $410 \mathrm{pA}) . B$, Summary of the effects of TTX and muscarine on the area of $\operatorname{ADPs}(n=8)$.

current (Fig. 6A, compare Control, Muscarine). After removal of muscarine from the bath, replacement of extracellular $\mathrm{NaCl}$ with choline chloride usually abolished action potentials (Fig. 6 A, Low Sodium). The amplitude of the current injection was increased so that the amplitude of the depolarization was equivalent to the action potential amplitude. There was a small AHP after this depolarization. Addition of muscarine $(10 \mu \mathrm{M})$ in low sodium solution did not result in the production of an ADP (Fig. 6A, + Muscarine). A summary of all such experiments is plotted in Figure $6 C$. The area of the afterpotential after a depolarizing current pulse in the presence of muscarine and low sodium was not significantly different from the area of the afterpotential in low sodium alone $(-14 \pm 10 \mathrm{mV} \cdot \mathrm{sec}$ vs low sodium plus muscarine $-8 \pm 10 \mathrm{mV} \cdot \mathrm{sec} ; p>0.63$ ) (Fig. $6 \mathrm{C}$, Low Sodium). However, the muscarinic ADP in normal saline was significantly different from the muscarinic afterpotential in low sodium (normal saline $236 \pm 56 \mathrm{mV} \cdot \mathrm{sec}$ vs low sodium $-8 \pm 10 \mathrm{mV} \cdot \mathrm{sec} ; p<$ 0.002). We concluded, therefore, that the muscarinic ADP is dependent on extracellular sodium.

Both sodium transport and slow sodium channels are sensitive to amiloride. We tested whether amiloride inhibited the muscarinic ADP in interneurons. In interneurons in which application of muscarine or ACh $(300 \mu \mathrm{M})$ normally produced an ADP (Fig. $6 B$ ), this afterpotential was not inhibited by amiloride (area 5255 $\mathrm{mV} \cdot \mathrm{sec}$ in normal saline vs $6688 \mathrm{mV} \cdot \mathrm{sec}$ in $100 \mu \mathrm{M}$ amiloride; $n=2$ ) (Fig. $6 B,+A C h$ ). Figure $6 C$ summarizes the effects of low sodium on the muscarinic ADP.

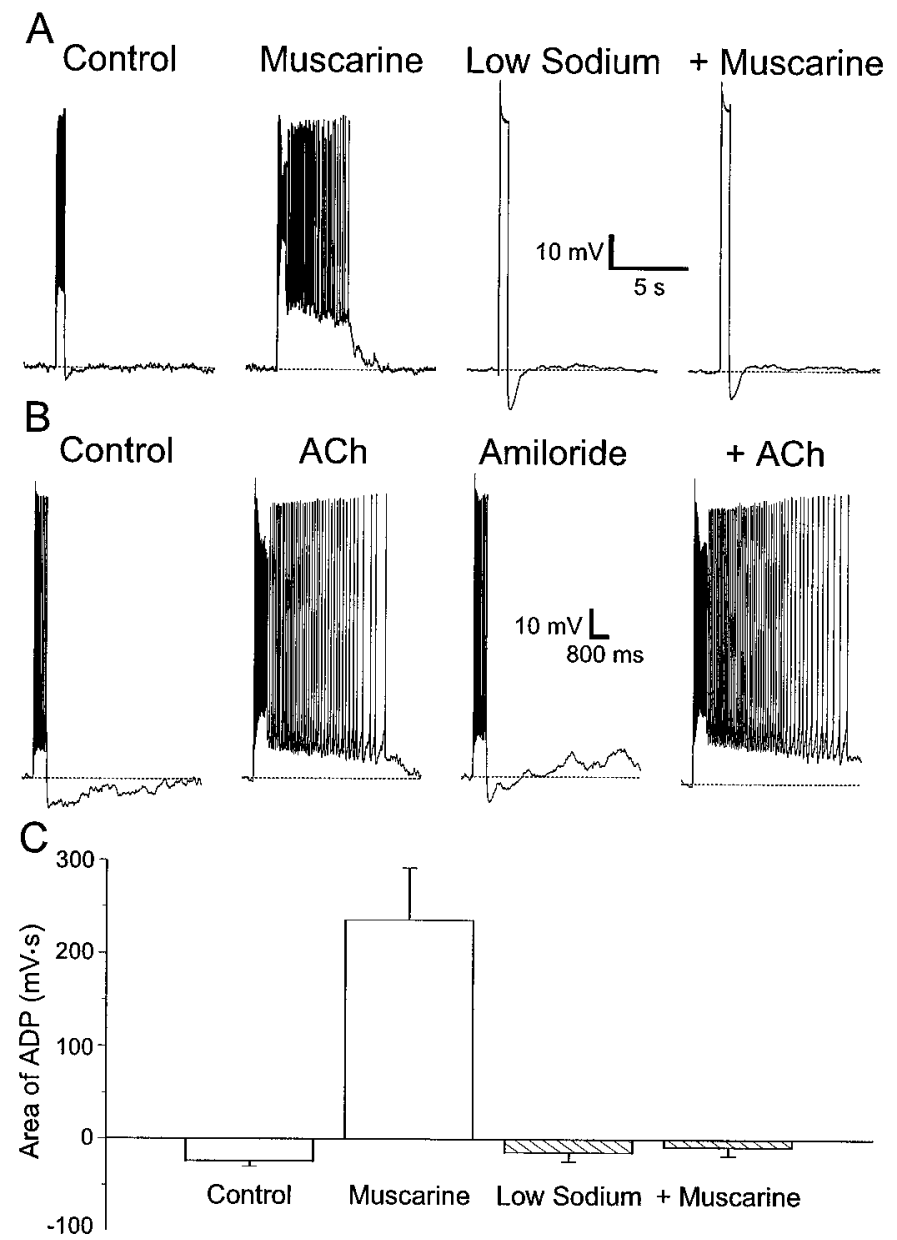

Figure 6. Sodium influx is required for ADPs. A, Left to right, In an SR interneuron, the AHP after a current injection $(600 \mathrm{msec}, 120 \mathrm{pA})$ was transformed into an ADP after application of muscarine $(10 \mu \mathrm{M})$. Replacement of $\mathrm{NaCl}$ by choline chloride blocks action potentials; however, the depolarizing current $(600 \mathrm{msec}, 520 \mathrm{pA})$ was still followed by an AHP. In low sodium, current depolarizing the cell to the same voltage as the peak of the action potential did not result in a muscarinic ADP. B, Left to right, Depolarizing current injection (600 msec, $100 \mathrm{pA})$ into an interneuron in SR resulted in an accommodating train of action potentials followed by an AHP. ACh $(300 \mu \mathrm{M})$, in the presence of nicotinic antagonists $(\alpha$-BgTx $100 \mathrm{nM}$; MEC $10 \mu \mathrm{M})$, promoted an ADP after the current injection. Amiloride $(100 \mu \mathrm{M})$ did not significantly affect the train of action potentials in response to depolarizing current and did not block the response to ACh. $C$, Plot of the area of the ADP with depolarizing current. Substitution of sodium by choline blocked the ADP $(n=10)$.

\section{Muscarinic ADPs can be elicited by synaptic potentials}

All ADPs studied to this point were elicited by depolarizations induced by injection of current into the cell through the recording electrode. We next determined whether a more physiological signal could induce a muscarinic ADP. Excitatory afferents onto interneurons were stimulated with an electrode placed in stratum oriens (SO), resulting in EPSPs that evoked a short burst of action potentials (Fig. 7, Control). After activation of muscarinic receptors, the EPSP was inhibited (data not shown). When the stimulus was increased to bring the amplitude of the EPSP back up to control levels, an ADP was produced. ADPs evoked by synaptic stimulation were of sufficient amplitude and duration to support long barrages of action potentials in the absence of any further stimulation $(n=3)$ (Fig. 7, middle). 


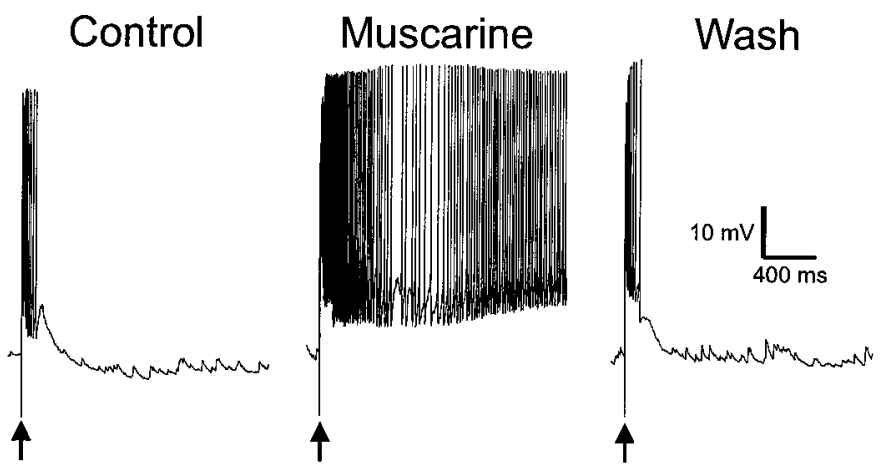

Figure 7. Muscarinic receptor activity produces ADPs after stimulusevoked excitatory postsynaptic potentials. Suprathreshold synaptic stimulation (arrows; $100 \mu \mathrm{sec}$ duration, $200 \mu \mathrm{A}$ amplitude) via a tungsten bipolar stimulating electrode placed in SO evoked an EPSP and a burst of action potentials (left). Synaptic stimulation in the presence of muscarine $(10 \mu \mathrm{M})$ produced a long-lasting (several seconds) burst of action potentials (ADP) after the EPSP $(n=3)$. Removal of muscarine eliminated the ADP response.

\section{Distribution of interneurons expressing a muscarinic ADP}

Muscarinic ADPs were observed in subsets of interneurons in all layers of CA1 (Table 1). The majority of cells demonstrating muscarinic ADPs were recorded in stratum radiatum (SR), although interneurons displaying ADPs were found in all layers of area CA1.

Muscarinic receptor activity is known to cause changes in the resting potentials in most CA1 interneurons (McQuiston and Madison, 1996; Parra et al., 1998). These can include depolarization, hyperpolarization, or biphasic responses (depolarization followed by a hyperpolarization). Interneurons having ADPs are no different in this regard, often showing changes in resting membrane potential in response to muscarinic receptor activity. There was no clearly dominant membrane potential response that accompanied ADPs: $34 \%$ of ADP-producing cells also depolarized, 26\% hyperpolarized, $14 \%$ had an initial hyperpolarization followed by a slower depolarization (biphasic), and $26 \%$ showed an ADP with no effect on the resting membrane potential. This is similar to the distribution of membrane potential changes seen with muscarinic receptor activity in the entire population of CA1 interneurons (i.e., those with and without ADPs) (McQuiston and Madison, 1999).

Although the location of the neuronal cell body sometimes provides information on potential interneuron anatomical subtypes, it alone is not sufficient to infer the function of interneurons (Freund and Buzsaki, 1996). To attempt a clearer definition of the types of interneurons that displayed muscarinic afterpotentials, interneurons having ADPs were filled with biocytin and identified by their dendritic and axonal arborizations. Four examples are shown in Figure 8. These interneurons displayed a variety of morphologies, and no layer lacked their axonal or dendritic arborizations. For example, a bilaminar interneuron had dendrites that extended from SO to SR and stratum lacunosum moleculare (SLM) and axons in the areas of SO and SR nearest the pyramidal cell body layer [stratum pyramidale (SP)] (Fig. $8 A$ ). The interneuron in Figure $8 B$ had a similar morphology; however, a significant portion of its axon was found in SP, and its dendrites were restricted to SO. Two other cells had axonal projections similar to the neurons in Figure 8, $A$ and $B$. The interneuron in Figure $8 C$ had dendrites in all layers of CA1; its axon arborized in the layers containing the proximal apical dendrites and cell bodies of CA1 pyramidal cells. The neuron in Figure $8 D$ also had its dendrites in all layers, but its axon arborized throughout the entire extent of SR and parts of SO as well. In all, there were eight interneurons whose axons arborized predominantly in SR and/or SLM; six of these had cell bodies in SR/SLM, and two had cell bodies in SO. In addition, the axons of two interneurons arborized exclusively in SO. Therefore, interneurons displaying muscarinic ADPs do not appear to be confined to a single well defined anatomical subtype.

\section{DISCUSSION}

In this study, we have described an ADP that occurs in a subpopulation of interneurons in hippocampal area CA1. This ADP arises after a train of action potentials only in the presence of muscarinic agonists.

\section{Ionic mechanism of the muscarinic ADP}

The ionic mechanisms producing the muscarinic ADP in CA1 interneurons are unlike any others that have been described for cortical neurons, including those in the hippocampus (Benardo and Prince, 1982; Gahwiler, 1984). In our study, the ADP was inhibited only by low extracellular sodium. Thus, we believe that muscarinic receptor activity produces an ADP by a novel ionic mechanism that involves sodium influx or transport.

In some types of neurons, an ADP is supported by calcium influx and is sensitive to inhibitors of VDCCs. This mechanism has been suggested to be the result of activation of a calciumdependent nonselective cation current (Schwindt et al., 1988; Andrade, 1991; Caeser et al., 1993; Fraser and MacVicar, 1996). A study of olfactory cortex pyramidal cells reported an ADP that was most likely caused by the inhibition of a calcium-activated potassium conductance that is thought to be responsible for repolarization after a burst of action potentials (Constanti and Bagetta, 1991; Constanti et al., 1993). In neocortical cells, the ADP is probably caused by activation of a sodium-calcium exchanger (Friedman et al., 1992). None of these mechanisms are likely to underlie the ADP described here because inhibition of calcium influx did not inhibit the ADP.

A persistent voltage-dependent sodium channel (French et al., 1990) was described to be the mechanism generating a small ADP in bursting CA1 pyramidal neurons. A similar mechanism does not appear to be responsible for the muscarinic ADP in this subset of interneurons, because it was not inhibited by TTX. However, the muscarinic ADP in interneurons does appear to depend on sodium influx or transport because the ADP was blocked by removal of extracellular sodium but not by amiloride at low concentrations that block some types of sodium channels (Garty and Palmer, 1997).

\section{Anatomical structure of interneurons with muscarinic ADPs}

Studies to date have suggested that interneurons with similar morphological structure do not necessarily subserve similar functions (Freund and Buzsaki, 1996). For example, interneurons with similar regions of axonal arborization may have different synaptic targets; some innervate principal cell dendrites (Gulyás and Freund, 1996), whereas others are specialized to innervate other interneurons (Acsady et al., 1996; Gulyás et al., 1996; Hájos et al., 1996; Blasco-Ibanez et al., 1998). Interneurons with overlapping axonal distributions can also contain different types of peptide cotransmitters, a factor that may indicate different functions (Freund and Buzsaki, 1996). Finally, interneurons with similar anatomical structure often show different firing properties; this may suggest different physiological functions in the hippocampal circuit (Buhl et al., 1994; Mott et al., 1997; Ali et al., 1998; Ali and Thomson, 1998; Vida et al., 1998). It is also the case that inter- 

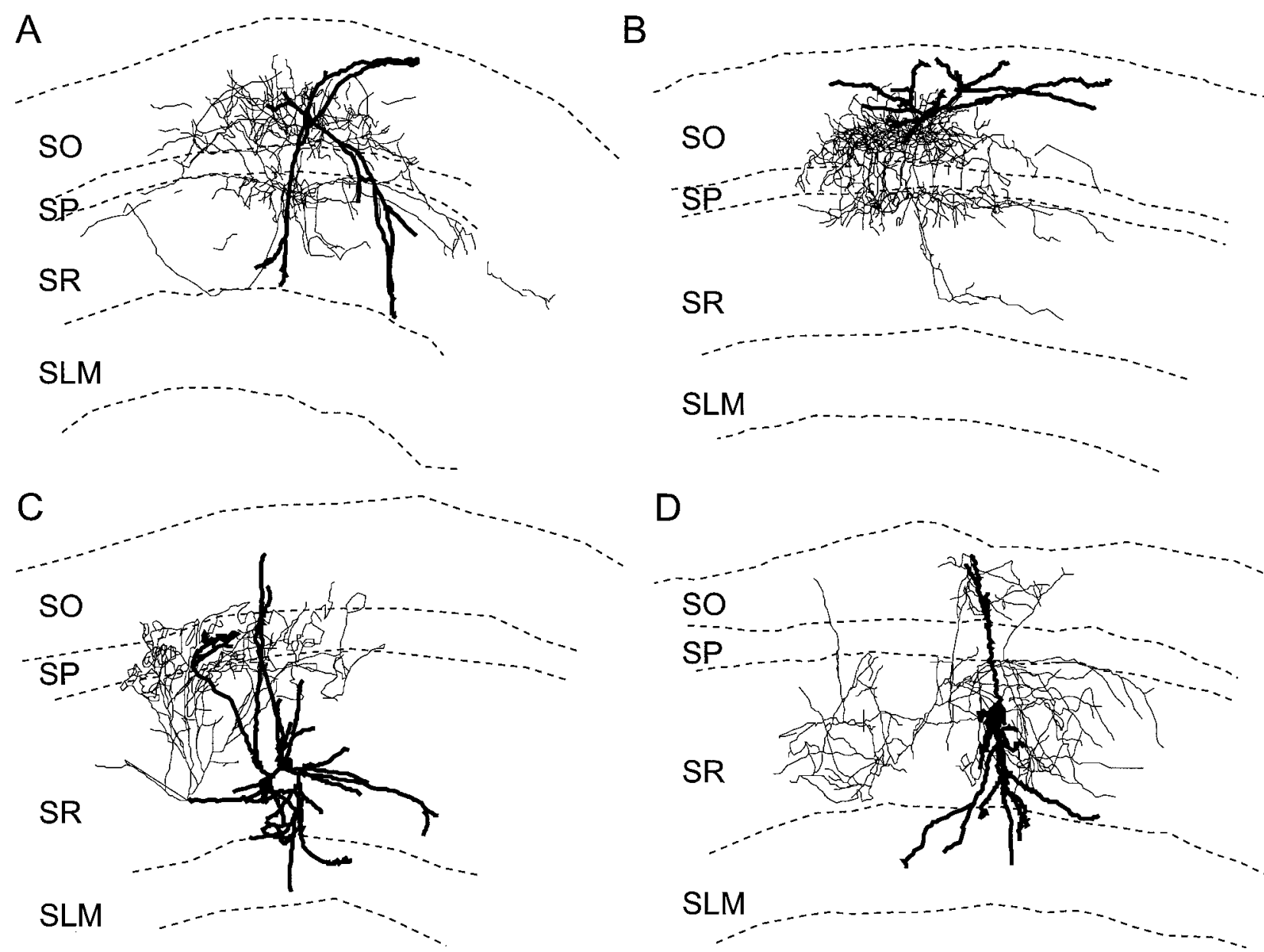

Figure 8. Neurolucida reconstructions of CA1 interneurons displaying muscarinic ADPs after injections of depolarizing current injections. Neurons in $A$ and $B$ responded to muscarine with membrane potential depolarizations and ADPs. $C, D$, These interneuron did not show a change in membrane potential to muscarine. Axons are shown in thin lines and dendrites in thick lines.

neurons with different morphologies may perform similar functions. Given this heterogeneity, it is not surprising that our morphological reconstruction of interneurons with muscarinic ADPs showed no distinct structural uniformity. The cell bodies of these neurons were found in all layers of CA1, albeit with greater frequency in SR and SLM. In addition, the dendritic and axonal distribution patterns of these interneurons did not permit coherent classification. Therefore, although our anatomical results appear to describe multiple types of interneurons displaying ADPs, these interneurons with varying morphological features may still belong to specific class(es) with similar or overlapping functions.

\section{Physiological function of muscarinic ADPs}

Muscarinic ADPs often occurred in conjunction with a change in the resting membrane potential, thereby increasing the complexity of possible neuronal outcomes during muscarinic agonist exposure. Some cells depolarized and had an ADP; in these cells, the ADP could act to augment the increased excitability of the cell. Cells that were hyperpolarized by muscarinic receptor activity would generally be inhibited. A combination of this inhibitory hyperpolarization and an excitatory ADP might serve to increase the signal-to-noise ratio of the interneuron to excitatory input. Relatively weak inputs would not bring the interneuron to action potential threshold during muscarinic hyperpolarization, but inputs strong enough to evoke an ADP would still result in enhanced action potential output from that same interneuron. Alternatively, the hyperpolarization could simply be limiting the barrage of output arising from the ADP. In cells that show a biphasic response accompanied by an ADP, a combination of these mechanisms might come into play. For biphasic responses in the absence of an ADP, the initial hyperpolarizing phase could be responsible for creating a time delay (phase shift) to the excitatory depolarizing phase of the muscarinic response. In biphasic cells that have an ADP, the ADP could reduce the time delay by either potentiating an excitatory input during the initial hyperpolarizing phase or by augmenting the depolarizing phase so that it generates action potentials earlier during the biphasic response. In cells that showed no membrane potential response to a muscarinic agonist, the ADP would serve as the sole mechanism for potentiating the response to excitatory input.

During elevated activity of septal cholinergic input, muscarinic activity changes the response to excitatory synaptic input of ADPproducing interneurons, from brief bursts of a few action potentials to long barrages of action potentials produced by the generation of the ADP. Given the complexity of muscarinic actions throughout the hippocampal circuitry, it is difficult to speculate about the circuit outcomes of a muscarinic ADP. Nonetheless, cholinergic promotion of a synaptically activated ADP could have a number of potential consequences for the function of the hippocampal cir- 
cuitry. Perhaps the simplest proposal on the function of the ADP is it might cause prolonged inhibition of all or part of the entire hippocampal circuit. Because the ADP is found across different interneuronal morphologies, the inhibition it generates might be distributed throughout all elements of the circuitry.

Prolonged inhibition supported by muscarinic ADPs could also conceivably participate in the competitive processes that are hypothesized to underlie many models of synaptic plasticity and development. These models often invoke a competition whereby "strong" inputs are enhanced and "weak" inputs are further weakened or even eliminated. An excitatory input that evoked an ADP might gain an advantage over other subsequent excitatory inputs, because it would act to inhibit the ability of those later inputs to fire their postsynaptic targets over a prolonged period of time. An excitatory input strong enough to evoke an ADP in interneurons would arrive at the principal cells before the ADPsupported inhibition and thus would be more likely to cause the principal cell to discharge. Inputs arriving later, during the ADPsupported inhibitory period, would be less likely to discharge the principal cells and, under some models of plasticity and competition, would be weakened.

Another possible function for the ADP could be to switch the interneuron from a predominantly GABA-releasing cell to one which releases increased levels of a peptide transmitter. Different types of interneurons contain a variety of neuropeptide cotransmitters, including peptides such as cholecystokinin, vasoactive intestinal peptide, neuropeptide $\mathrm{Y}$, somatostatin, and opioids (Freund and Buzsaki, 1996). Peptide release requires higher frequencies of presynaptic action potentials than classical transmitters (Miller, 1990). Thus, peptide release would be more likely to occur as the result of the action potential barrage stimulated by muscarinic ADPs.

\section{REFERENCES}

Acsady L, Gorcs TJ, Freund TF (1996) Different populations of vasoactive intestinal polypeptide-immunoreactive interneurons are specialized to control pyramidal cells or interneurons in the hippocampus. Neuroscience 73:317-334.

Ali AB, Thomson AM (1998) Facilitating pyramid to horizontal oriensalveus interneurone inputs: dual intracellular recordings in slices of rat hippocampus. J Physiol (Lond) 507:185-199.

Ali AB, Deuchars J, Pawelzik H, Thomson AM (1998) CA1 pyramidal to basket and bistratified cell EPSPs: dual intracellular recordings in rat hippocampal slices. J Physiol (Lond) 507:201-217.

Andrade R (1991) Cell excitation enhances muscarinic cholinergic responses in rat association cortex. Brain Res 548:81-93.

Azouz R, Jensen MS, Yaari Y (1996) Ionic basis of spike afterdepolarization and burst generation in adult rat hippocampal CA1 pyramidal cells. J Physiol (Lond) 492:211-223.

Benardo LS, Prince DA (1982) Cholinergic excitation of mammalian hippocampal pyramidal cells. Brain Res 249:315-331.

Blasco-Ibanez JM, Martinez-Guijarro FJ, Freund TF (1998) Enkephalin-containing interneurons are specialized to innervate other interneurons in the hippocampal CA1 region of the rat and guinea-pig. Eur J Neurosci 10:1784-1795.

Bolam JP (1992) Experimental neuroanatomy: a practical approach. Oxford: Oxford UP.

Buhl EH, Halasy K, Somogyi P (1994) Diverse sources of hippocampal unitary inhibitory postsynaptic potentials and the number of synaptic release sites. Nature 368:823-828.
Caeser M, Brown DA, Gähwiler BH, Knöpfel T (1993) Characterization of a calcium-dependent current generating a slow afterdepolarization of CA3 pyramidal cells in rat hippocampal slice cultures. Eur J Neurosci 5:560-569.

Cole AE, Nicoll RA (1983) Acetylcholine mediates a slow synaptic potential in hippocampal pyramidal cells. Science 221:1299-1301.

Constanti A, Bagetta G (1991) Muscarinic receptor activation induces a prolonged post-stimulus afterdepolarization with a conductance decrease in guinea-pig olfactory cortex neurones in vitro. Neurosci Lett 131:27-32.

Constanti A, Bagetta G, Libri V (1993) Persistent muscarinic excitation in guinea-pig olfactory cortex neurons: involvement of a slow poststimulus afterdepolarizing current. Neuroscience 56:887-904.

Crill WE (1996) Persistent sodium current in mammalian central neurons. Annu Rev Physiol 58:349-362.

Dodt HU, Zieglgansberger W (1990) Visualizing unstained neurons in living brain slices by infrared DIC-videomicroscopy. Brain Res 537:333-336.

Fraser DD, MacVicar BA (1996) Cholinergic-dependent plateau potential in hippocampal CA1 pyramidal neurons. J Neurosci 16:4113-4128.

French CR, Sah P, Buckett KJ, Gage PW (1990) A voltage-dependent persistent sodium current in mammalian hippocampal neurons. J Gen Physiol 95:1139-1157.

Freund TF, Buzsaki G (1996) Interneurons of the hippocampus. Hippocampus 6:347-470.

Friedman A, Arens J, Heinemann U, Gutnick MJ (1992) Slow depolarizing afterpotentials in neocortical neurons are sodium and calcium dependent. Neurosci Lett 135:13-17.

Gähwiler BH (1984) Facilitation by acetylcholine of tetrodotoxin-resistant spikes in rat hippocampal pyramidal cells. Neuroscience 11:381-388.

Garty H, Palmer LG (1997) Epithelial sodium channels: function, structure, and regulation. Physiol Rev 77:359-396.

Gulyás AI, Freund TF (1996) Pyramidal cell dendrites are the primary targets of calbindin D28k-immunoreactive interneurons in the hippocampus. Hippocampus 6:525-534.

Gulyás AI, Hájos N, Freund TF (1996) Interneurons containing calretinin are specialized to control other interneurons in the rat hippocampus. J Neurosci 15:3397-3411.

Hájos N, Acsady L, Freund TF (1996) Target selectivity and neurochemical characteristics of VIP-immunoreactive interneurons in the rat dentate gyrus. Eur J Neurosci 8:1415-1431.

MacVicar BA (1984) Infrared video microscopy to visualize neurons in the in vitro brain slice preparation. J Neurosci Methods 12:133-139.

McQuiston AR, Madison DV (1996) Postsynaptic actions of cholinergic receptor activation on multiple types of interneurons in CA1 regions of the rat hippocampus. Soc Neurosci Abstr 22:786.

McQuiston AR, Madison DV (1999) Muscarinic receptor activity has multiple effects on the resting membrane potentials of CA1 hippocampal interneurons. J Neurosci 19:5693-5702.

Miller RJ (1990) Receptor-mediated regulation of calcium channels and neurotransmitter release. FASEB J 4:3291-3299.

Mott DD, Turner DA, Okazaki MM, Lewis DV (1997) Interneurons of the dentate-hilus border of the rat dentate gyrus: morphological and electrophysiological heterogeneity. J Neurosci 17:3990-4005.

Parra P, Gulyás AI, Miles R (1998) How many subtypes of inhibitory cells in the hippocampus? Neuron 20:983-993.

Reece LJ, Schwartzkroin PA (1991) Effects of cholinergic agonists on two non-pyramidal cell types in rat hippocampal slices. Brain Res 566:115-126.

Schwindt PC, Spain WJ, Foehring RC, Chubb MC, Crill WE (1988) Slow conductances in neurons from cat sensorimotor cortex in vitro and their role in slow excitability changes. J Neurophysiol 59:450-467.

Velumian AA, Zhang L, Pennefather P, Carlen PL (1997) Reversible inhibition of IK, IAHP, Ih and ICa currents by internally applied gluconate in rat hippocampal pyramidal neurones. Pflügers Arch 433:343-350.

Vida I, Halasy K, Szinyei C, Somogyi P, Buhl EH (1998) Unitary IPSPs evoked by interneurons at the stratum radiatum-stratum lacunosummoleculare border in the CA1 area of the rat hippocampus in vitro. J Physiol (Lond) 506:755-773. 